\title{
Immunochemical structure of the OmpD porin from Salmonella typhimurium
}

\author{
Shiva P. Singh, ${ }^{1}$ Stephanie Miller, ${ }^{1}$ Yvonne U. Williams, ${ }^{1}$ \\ Kenneth E. Rudd ${ }^{2}$ and Hiroshi Nikaido ${ }^{3}$ \\ Author for correspondence: Shiva P. Singh. Tel: +1 334229 4301. Fax: +1 3342294288. \\ e-mail: SPSINGH@ASU.ALASU.EDU
}

1 Biomedical Research and Training Programs, Alabama State University, Montgomery, AL 36101, USA

2 National Center for Biotechnology Information, National Library of Medicine, National Institutes of Health, Bethesda, MD 20894, USA

3 Department of Molecular and Cell Biology, University of California, Berkeley, CA 94720, USA

\begin{abstract}
The OmpD porin was isolated and purified from Salmonella typhimurium strain SH 7454 (ompC::Tn10), digested with cyanogen bromide (CNBr) and the peptide fragments were separated by SDS-PAGE. N-terminal sequencing identified a total of $\mathbf{9 6}$ residues from four distinct peptides. The sequence showed that OmpD is homologous to NmpC (75\% identity), LC (75\%) and OmpC (70\%) from Escherichia coli, and OmpC (68\%) from S. typhimurium. The sequence was essentially identical to the translated sequence of an nmpC-like gene of S. typhimurium, currently placed at 38.6 centisomes of the chromosome. Our results and other data suggest, however, that this gene is actually the ompD gene, which is more correctly placed in the 34 centisome region of the chromosome. The CNBr-generated peptides were also screened with 16 anti-S. typhimurium OmpD monoclonal antibodies by Western blotting. These results, in conjunction with the prediction of the OmpD folding pattern based on the known three-dimensional structure of $E$. coli O $\mathrm{mpF}$, showed a close immunological relationship among S. typhimurium OmpD and $E$. coli NmpC and LC, and a strong conservation of sequences within the transmembrane $\beta$ strands of these porins and E. coli OmpC, PhoE and OmpF, and Salmonella typhi OmpC.
\end{abstract}

Keywords: Salmonella typhimurium, OmpD, porins, amino acid sequence, monoclonal antibodies

\section{INTRODUCTION}

Porins are a family of pore-forming proteins commonly found in the outer membrane (OM) of Gram-negative bacteria (Lugtenberg \& van Alphen, 1983; Nikaido \& Vaara, 1985). They exist as homo- or heterotrimers (Gehring \& Nikaido, 1989) in vivo and function as waterfilled channels allowing passive diffusion of nutrients across the OM (Nikaido \& Vaara, 1985). Two general porins, $\mathrm{OmpC}$ and $\mathrm{OmpF}$, are produced by Escherichia coli and Salmonella typhimurium, and a third porin, PhoE, with a preference for negatively charged solutes such as phosphate, is produced by both organisms when cells are cultured under special conditions (Lugtenberg \& van Alphen, 1983; Nikaido \& Vaara, 1985). The threedimensional structures of $\mathrm{OmpF}$ and PhoE from E. coli

Abbreviation: $\mathrm{OM}$, outer membrane.

The PIR accession number for the OmpD sequences reported in this paper is $A 57983$.
(Cowan et al., 1992) and two porins from Rbodobacter species (Kreusch \& Schulz, 1994; Weiss et al., 1991) have been determined by $\mathrm{X}$-ray crystallography. These proteins form hollow cylinders that consist of anti-parallel $\beta$ strands; long hydrophilic loops of irregular length and short $\beta$-hairpin turns connect these strands on the external and periplasmic surfaces of the OM bilayer, respectively (Cowan \& Rosenbusch, 1994; Cowan et al., 1992; Jap et al., 1991; Jeanteur et al., 1994; Klebba et al., 1990; Nikaido, 1992; Struyve et al., 1993; Weiss et al., 1991). The primary structure of porins varies significantly among Gram-negative bacteria (Gerbl-Rieger et al., 1991), but amphiphilic $\beta$ strands ( $7-14$ residues each) in the porin barrel are structurally conserved (Gerbl-Rieger et al., 1991 ; Jeanteur et al., 1994). Generally, porins contain five or more surface epitopes, 6-25 residues in length (Klebba et al., 1990; Puente et al., 1989; Singh et al., 1992, 1995, 1996; Tommassen et al., 1993; van der Ley et al., 1986b), which are partially obscured by the lipopolysaccharide (LPS) core and completely blocked by O-antigen sugars (Bentley \& Klebba, 1988; Bowden et al., 1995; van der 
Ley et al., 1986a). These proteins also contain conserved buried epitopes that are localized on the transmembranous $\beta$ strands (Jeanteur et al., 1994; Klebba et al., 1990; Puente et al., 1989; Singh et al., 1992, 1995, 1996; Tommassen et al., 1993).

OmpD, a fourth general porin, is of special interest because it is regularly found in S. typhimurium but is absent from E. coli (Lee \& Schnaitman, 1980; Lugtenberg \& van Alphen, 1983; Nikaido \& Vaara, 1985). This protein is regulated in a manner similar to $E$. coli porins Lc, encoded by bacteriophage PA-2, and $\mathrm{NmpC}$, which also appears to be part of the integrated defective phage genome (Blasband et al., 1986; Highton et al., 1985). All three proteins are subject to catabolite repression (Lee \& Schnaitman, 1980; Pugsley \& Schnaitman, 1978) and their biosynthesis, unlike that of $\mathrm{OmpC}$ and $\mathrm{OmpF}$, is not affected by the osmolarity of the growth medium (Pugsley \& Schnaitman, 1978; Singh et al., 1987). Recently, Hongo et al. (1994) sequenced a 849 bp segment of DNA located near the methyl-viologen-resistance-encoding gene on the S. typhimurium chromosome. The $\mathrm{N}$-terminally truncated protein encoded by this segment was termed ' $\mathrm{NmpC}$ ' of $S$. typhimurium because it is $83 \%$ identical to $E$. coli $\mathrm{NmpC}$.

We have previously reported, based on the Western immunoblot reactivity of anti-OmpD $\mathrm{mAbs}$, that $E$. coli $\mathrm{NmpC}$, S. typhimurium OmpD and the Lc porins form a subfamily that is part of a larger family that includes OmpF, OmpC and PhoE (Singh et al., 1992). The porins in this family show roughly $65 \%$ identity and $80 \%$ similarity (Blasband et al., 1986; Mizuno et al., 1983; Puente et al., 1989). The amino acid sequences of $\mathrm{NmpC}$ and Lc from E. coli (Blasband et al., 1986) and the NmpClike protein from $S$. typhimurium (Hongo et al., 1994) are known; however, the three-dimensional structure of none of these proteins is yet resolved, and the $S$. typhimurium OmpD has not been sequenced either. In this study, we identified 96 residues of $S$. typhimurium $\mathrm{OmpD}$ by $\mathrm{N}$ terminal analysis of cyanogen bromide $(\mathrm{CNBr})$-generated peptides which show that $\mathrm{OmpD}$ is identical to the NmpC-like protein (Hongo et al., 1994); the OmpD sequence also showed $68-75 \%$ identity with $\mathrm{NmpC}$ and Lc from E. coli, and OmpC from both $E$. coli and $S$. typhimurium. We also used a panel of 16 anti-OmpD mAbs to define several epitopes of $S$. typhimurium OmpD. The $\mathrm{CNBr}$-cleaved peptides containing internal Met residues and antiporin $\mathrm{mAbs}$, as employed in this study, have been used previously to study the immunochemical structure of other bacterial porins (Haase et al., 1994; Klebba et al., 1990; Murphy \& Bartos, 1988; Mutharia \& Hancock, 1985; Rawling et al., 1995; Singh et al., 1995). A folding pattern of OmpD is proposed; it predicts the same exposed loops, periplasmic turns and membrane-spanning $\beta$ strands of this protein as seen in the known threedimensional structure of E. coli OmpF (Cowan et al., 1992).

\section{METHODS}

Bacterial strain and growth conditions. The culture media and growth conditions used in this study have been described previously (Singh et al., 1992). S. typhimurium strains SH 7454,
SH 7455 and SH 7457 (galE rough mutants producing Rc chemotype LPS; provided by P. H. Mäkelä, National Public Health Institute, Helsinki, Finland) are $\operatorname{omp} c:: \operatorname{Tn} 10$, ompD::Tn10 ompC::Tn10 and $o m p D:: \operatorname{Tn} 10$ derivatives of $\mathrm{SH}$ 6749 (Sukupolvi et al., 1984) and express the OmpD, OmpF and OmpC proteins, respectively, as their sole porin when grown under high osmolarity conditions (Singh et al., 1987, 1992). E. coli strains JF 1054 (provided by J. Foulds, National Institute of Allergy and Infectious Diseases, MA, USA), PC 2086 (provided by J. Tommassen, State University of Utrecht, The Netherlands) and JF 703, JF 701 and JF 694 (provided by K. Gehring, University of California, Berkeley, USA) express $\mathrm{NmpC}, \mathrm{Lc}, \mathrm{OmpC}, \mathrm{OmpF}$ and PhoE, respectively, as their sole porins (Gehring \& Nikaido, 1989; Verhoef et al., 1987).

Isolation and purification of OmpD. The native porin (trimer) was isolated and purified by solubilization of bacterial cell envelopes in $1 \%(\mathrm{w} / \mathrm{v})$ SDS $/ 0.5 \mathrm{M} \mathrm{NaCl}$ followed by size exclusion chromatography with Sephacryl S-200 (Gehring \& Nikaido, 1989). Denatured monomeric porin was prepared by boiling the trimer at $100{ }^{\circ} \mathrm{C}$ for $5 \mathrm{~min}$ in $1 \%$ SDS (Klebba et al., 1990).

The OM was isolated by suspending the cell pellet in $10 \mathrm{mM}$ HEPES buffer, $\mathrm{pH} \mathrm{7.4}$ and passing the suspension twice at 16000 p.s.i. $(110400 \mathrm{kPa})$ through a French pressure cell (American Instrument). OM fragments were then purified by sucrose density gradient centrifugation (Smit et al., 1975). LPS (R type) was isolated from S. typhimurium SH 7454 by the phenol/water extraction procedure described by Galanos $e t$ al. (1969).

Production of anti-OmpD mAbs. BALB/c mice were immunized with OmpD monomer and cell fusion was carried out as described previously (Singh et al., 1992). Hybridomas were selected in hypoxanthine-aminopterin-thymidine medium (Kearney, 1984). Culture fluids from wells with colonies were assayed by ELISA against porin monomers, trimers, OM, LPS and whole cells. Hybridomas of interest were cloned by limiting dilution and injected into BALB/c mice for production of ascitic tumours (Kearney, 1984). The class and subclass of $\mathrm{mAbs}$ were determined by ELISA with goat antisera against mouse heavy and light chains $\mu, \gamma_{1}, \gamma_{2 a}, \gamma_{2 b}, \gamma_{3}, \kappa$ and $\lambda$ (Fisher).

ELISA. ELISA was performed as described previously (Singh $e t$ al., 1992).

CNBr digestion of OmpD. Protein concentrations were measured with the Micro BCA protein assay reagent (Pierce), with BSA as standard. Five milligrams of OmpD monomer was precipitated, washed with acetone and digested with $250 \mathrm{mg}$ $\mathrm{CNBr}$ in $500 \mu \mathrm{l} 70 \%(\mathrm{v} / \mathrm{v})$ trifluoroacetic acid (Garten et al., 1975 ) by overnight incubation at room temperature. The digested sample was lyophilized twice, and then suspended in SDS-sample buffer $\left(1 \mathrm{mg} \mathrm{ml}^{-1}\right)$ and stored at $-80^{\circ} \mathrm{C}$ for later use in gel electrophoresis.

Gel electrophoresis. SDS-PAGE was performed on 10-20\% (w/v) polyacrylamide linear gradient gels as described previously (Singh et al., 1992). The gel was stained with ammoniacal silver stain and the molecular masses of $\mathrm{OmpD}$ fragments were determined using a standard curve. For Western blots, proteins were electrophoretically transferred to nitrocellulose paper and immunoblots were performed as described previously (Pai $e t$ al., 1992; Singh et al., 1992).

Amino acid composition and $\mathbf{N}$-terminal sequencing. Purified OmpD or its CNBr-generated peptides were separated by SDSPAGE and transferred to Immobilon-P PVDF membranes (Millipore). The transfer was carried out in $10 \mathrm{mM}$ CAPS according to the procedure of Matsudaira (1987). Protein bands 
Table 1. Epitope specificity of anti-S. typhimurium OmpD mAbs

mAbs were raised to the purified OmpD monomer (DM). They were also characterized by ELISA as described previously (Singh et al., 1992); all bound purified OmpD monomer but none reacted with OmpD trimer, OM, LPS or whole cells (data not shown).

\begin{tabular}{|c|c|c|c|c|c|c|}
\hline \multirow[t]{2}{*}{$\mathbf{m A b}$} & \multirow[t]{2}{*}{ Isotype } & \multicolumn{5}{|c|}{ mAb reactivity in Western blots* } \\
\hline & & $\begin{array}{c}\text { E. coli } \\
\text { NmpC }\end{array}$ & $\begin{array}{c}\text { E. coli } \\
\text { Lc }\end{array}$ & $\begin{array}{l}\text { E. coli } \\
\text { OmpC }\end{array}$ & $\begin{array}{c}\text { S. typhi } \\
\text { OmpC }\end{array}$ & $\begin{array}{l}\text { E. coli } \\
\text { PhoE }\end{array}$ \\
\hline DM51.1 & $\operatorname{IgG}_{1}$ & ++ & ++ & + & + & ++ \\
\hline DM62.1 & $\operatorname{IgG}_{1}$ & ++ & ++ & ++ & + & ++ \\
\hline DM9.2† & $\mathrm{IgG}_{2} \mathrm{~b}$ & ++ & ++ & ++ & ++ & ++ \\
\hline DM20.2† & $\mathrm{IgG}_{2} \mathrm{~b}$ & + & ++ & ++ & ++ & + \\
\hline $\mathrm{DM} 22.2 \dagger$ & $\operatorname{IgG}_{1}$ & ++ & ++ & ++ & ++ & ++ \\
\hline DM49.2 & $\mathrm{IgG}_{2} \mathrm{~b}$ & ++ & ++ & + & + & + \\
\hline DM57.2 & $\mathrm{IgG}_{2} \mathrm{~b}$ & + & + & ++ & ++ & + \\
\hline DM2.1 & $\operatorname{IgG}_{2} \mathrm{a}$ & ++ & ++ & ++ & + & ++ \\
\hline DM12.2 & $\operatorname{IgG}_{2} \mathrm{~b}$ & ++ & ++ & ++ & + & + \\
\hline DM11.2 & $\mathrm{IgG}_{2} \mathrm{~b}$ & ++ & ++ & ++ & ++ & + \\
\hline DM60.3 & $\operatorname{IgG}_{2} \mathrm{~b}$ & ++ & ++ & + & + & + \\
\hline $\mathrm{DM} 26.1 \dagger$ & $\operatorname{IgG}_{2} \mathrm{~b}$ & ++ & ++ & - & + & + \\
\hline DM46.2† & $\operatorname{IgM}$ & + & + & - & ++ & ++ \\
\hline DM5.1 & $\mathrm{IgG}_{1}$ & ++ & ++ & - & - & - \\
\hline DM19.1† & $\operatorname{IgG}_{2} \mathrm{a}$ & ++ & ++ & - & - & - \\
\hline DM24.4† & $\operatorname{IgG1}$ & ++ & ++ & - & - & - \\
\hline
\end{tabular}

*Cell envelopes from bacterial strains selectively expressing E. coli porins NmpC (JF 1054), Lc (PC 2086), OmpC (JF 703), OmpF (JF 701) and PhoE (JF 694), and S. typhi OmpC (Singh et al., 1992) were separated by SDS-PAGE and the immunoblots were performed as described previously (Singh et al., 1992). Immunoblot reactions of anti-porin $\mathrm{mAbs}$ were evaluated in comparison with the reactions of normal mouse serum and ascites from the cell fusion partner P3x63-Ag8.653, which is a nonsecretor of immunoglobulins (Kearney, 1984). Reactions were scored as negative $(-)$, weakly positive (+) or strongly positive $(++)$ in comparison with the intensity of reaction with the immunogen porin and negative controls. Immunoblot reactions of the $\mathrm{mAbs}$ with E. coli OmpF (data not shown) were generally similar to those indicated for E. coli OmpC.

† DM 9.2, 20.2, 22.2, 26.1, 46.2, 19.1 and 24.4 were designated mAbs 22, 18, 24, 29, 35, 27 and 25, respectively, in our previous report (Singh et al., 1992).

on the PVDF membranes were localized by staining with $0 \cdot 1 \%$ amido black. The sections of the membrane containing the desired bands were excised, hydrolysed with $6 \mathrm{M} \mathrm{HCl}$ and analysed in a Beckman model 6300 amino acid analyser. For $\mathrm{N}$ terminal sequencing, $\mathrm{CNBr}$-generated peptides on PVDF membranes were applied to a Beckman model LF3000G sequencer. The amino acid sequences of $S$. typhimurium OmpD were compared with those of $\mathrm{NmpC}$ (Blasband et al., 1986), Lc (Blasband et al., 1986) and OmpC (Mizuno et al., 1983) from $E$. coli, and OmpC (Puente et al., 1989; Singh et al., 1995) and the NmpC-like protein (Hongo et al., 1994) from S. typhimurium, with the Best Fit program of the University of Wisconsin Genetics Computer Group, Madison, WI, USA.

PCR. A PCR amplification was performed using two primers that are homologous to nt 36-54 (5'-GACAAAGACAAAACCCGT'T-3') and 775-757 (5'-CG'TCCAGCAGGT'TGATTTT-3') on the $S$. typhimurium nmpC-like gene (GenBank accession number D26057; Hongo et al., 1994). These primers were used to amplify genomic DNA from $S$. typhimurium strains SH $7454\left(\mathrm{OmpD}^{+}\right)$, SH 7455 and SH 7457 . The latter two strains contain a mutation made by a $\operatorname{Tn} 10$ insertion $(o m p D 159:: \operatorname{Tn} 10$
$\mathrm{Tc}^{\mathrm{S}}$ ) and were subsequently selected for a tetracycline sensitive derivative that does not express $\mathrm{OmpD}$. The reaction mixture $(50 \mu \mathrm{l})$ contained $200 \mathrm{pmol}$ of each primer, $200 \mu \mathrm{M}$ of each deoxynucleoside triphosphate, 1.25 units Taq DNA polymerase and approximately $200 \mathrm{pmol}$ of genomic DNA as template. Each amplification cycle included three reaction steps: $1 \mathrm{~min}$ at $94^{\circ} \mathrm{C}$ for denaturation, $1 \mathrm{~min}$ at $55^{\circ} \mathrm{C}$ for annealing and $2 \mathrm{~min}$ at $72{ }^{\circ} \mathrm{C}$ for extension. All together, 40 cycles were carried out by using a Programable Thermocycler-100 (MJ Research). The products of amplification were visualized on an ethidiumbromide-stained agarose gel.

\section{RESULTS AND DISCUSSION}

\section{mAb specificities}

Nine previously unreported mAbs (DM 51.1, 62.1, 49.2, $57.2,2.1,12.2,11.2,60.3$ and 5.1$)$ were raised to $S$. typhimurium $\mathrm{OmpD}$ (Table 1). The test panel also included seven previously reported anti-OmpD mAbs (DM 9.2, 20.2, 22.2, 26.1, 46.2, 19.1 and 24.4; Table 1), all of which 
Eco NmpC

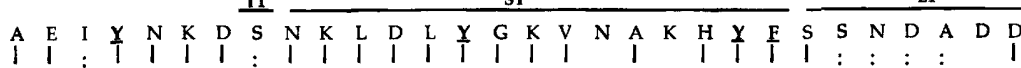

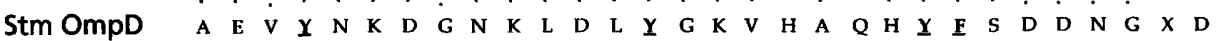

Stm 'NmpC'

Eco NmpC Stm OmpD $\quad$ G $D$

Stm 'NmpC'

Eco NmpC

Stm OmpD

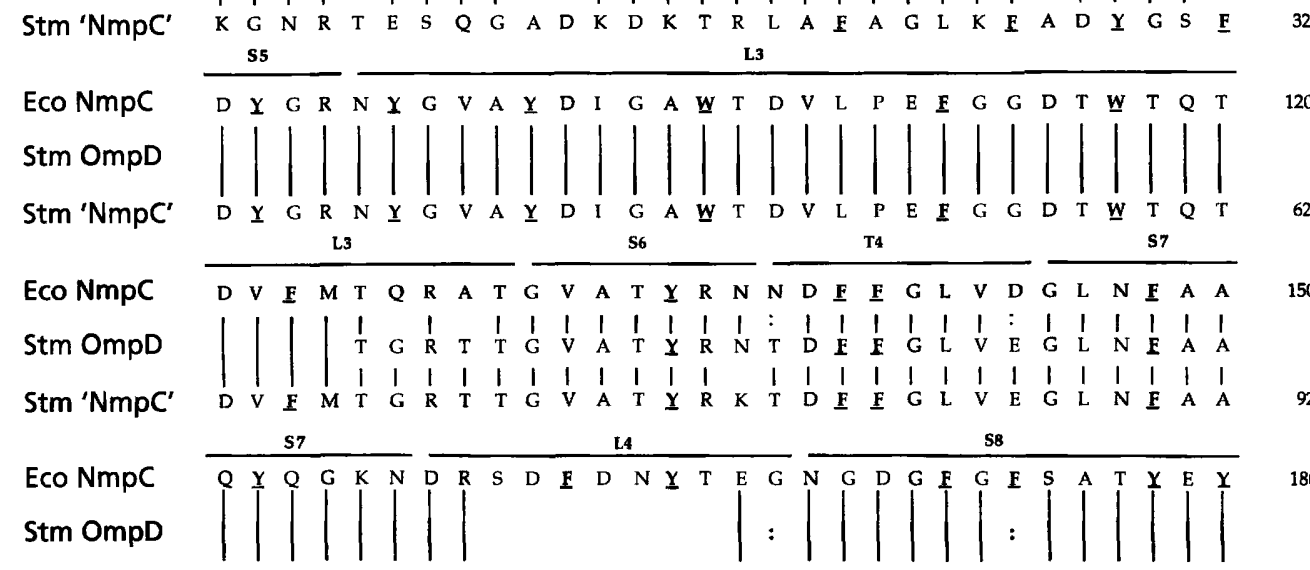

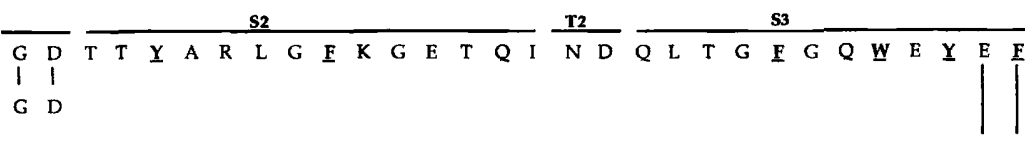

$-\frac{\mathrm{L} 2}{\mathrm{~L}}$

E $\mathbf{F}$

$\begin{array}{llllllllllllllllllllllllllllll}K & G & N & R & A & E & S & Q & G & S & S & K & D & K & T & R & L & A & F & A & G & L & K & E & G & D & \underline{Y} & G & S & I\end{array}$

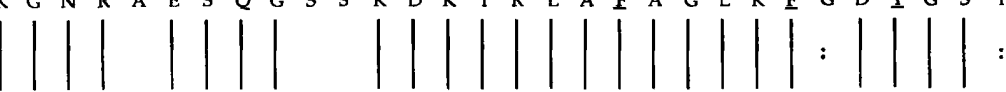

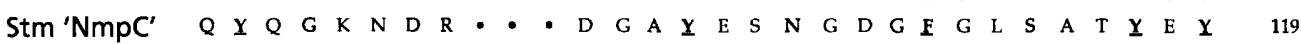

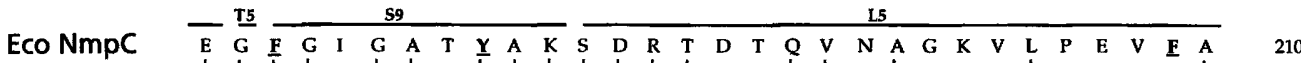

Stm OmpD

Stm 'NmpC'

E G E G V G A A

46

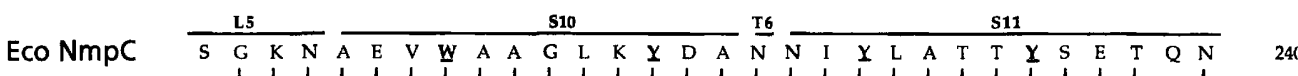

Stm OmpD

Stm 'NmpC'

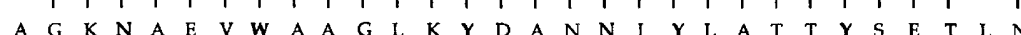

Eco $\mathrm{NmpC}$

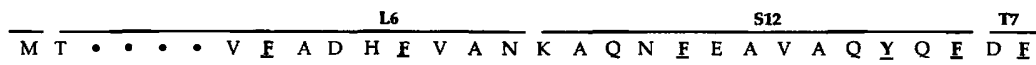

Stm OmpD

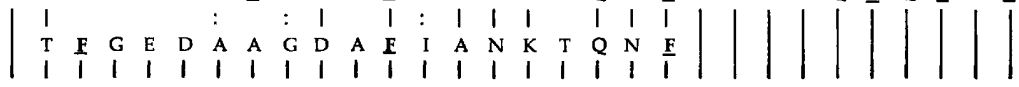

Stm 'NmpC'

M T F G E

Eco NmpC

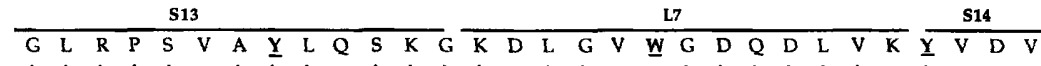

Stm OmpD

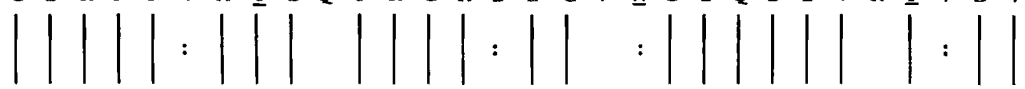

Stm 'NmpC'

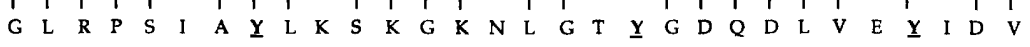

Eco NmpC

Stm OmpD

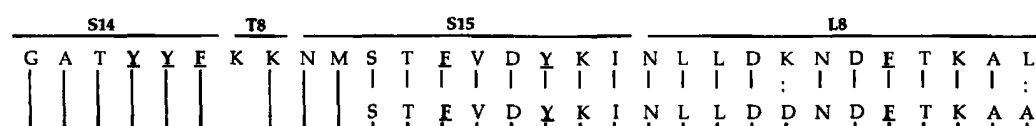

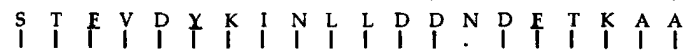

Stm ' $\mathrm{NmpC}$

$\begin{array}{llllllllllllllllllllllllllllll}G & A & T & Y & Y & F & N & K & N & M & S & T & F & V & D & Y & K & I & N & L & L & D & D & S & D & F & T & K & A & A\end{array}$

296

236

Eco NmpC $\frac{\text { L8 }}{\text { G V S T D D I v A V G L V Y Q F }}{ }_{342}$

Stm OmpD

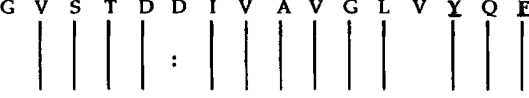

$\begin{array}{llllllllllllllllll}\text { Stm 'NmpC' } & \text { K } & \text { V } & \text { S } & \text { T } & \text { D } & \text { N } & \text { I } & \text { V } & \text { A } & \text { V } & \text { G } & \text { L } & \text { N } & \underline{Y} & Q & \underline{F} & 282\end{array}$

Fig. 1. For legend see facing page. 
recognized buried epitopes on the OmpD porin (Singh $e t$ al., 1992, 1996). Specificities of the new mAbs were determined by their reactivity with purified porins, LPS, $\mathrm{OM}$ and intact whole cells in ELISA and their immunoblot reactivity with either denatured whole cell or cell envelope lysates. All the new $\mathrm{mAbs}$ bound purified OmpD monomer but did not react with porin trimer, OM, LPS or intact whole cells (data not shown); their epitope(s) are buried, either in the membrane bilayer or in the tertiary structure of $\mathrm{OmpD}$.

\section{Identity of CNBr-generated fragments}

Since $\mathrm{CNBr}$ cleaves polypeptides at the $\mathrm{C}$-terminal end of Met residues (Garten et al., 1975), complete digestion of E. coli $\mathrm{NmpC}$ (and possibly S. typhimurium OmpD; see below) with $\mathrm{CNBr}$ would produce four peptides: aa $1-124,125-241,242-306$ and 307-342 with calculated molecular masses of $13905,12779,7401$ and $4010 \mathrm{Da}$, respectively. Likewise, E. coli Lc would produce four peptides that would be identical to $\mathrm{NmpC}$ in terms of their amino acid positions with only minor differences in calculated molecular masses. However, we detected at least five bands (fragments) with estimated molecular masses of $31 \cdot 0,24.5,15 \cdot 0,13 \cdot 2$ and $10.5 \mathrm{kDa}$ (f1-f5, respectively) in $\mathrm{CNBr}$ digests of $S$. typhimurium $\mathrm{OmpD}$ (data not shown). These fragments were identified from their N-terminal sequence(s) (see below), relative electrophoretic mobilities and/or by the process of elimination. Each fragment contained one to three distinct $\mathrm{N}$-terminal sequences (in order of relative abundance): $\mathrm{f1}$, aa 1-241 and $307-342 ; \mathrm{f} 2,125-342 ; \mathrm{f3}, 1-124,242-342$ and 125-241; f4, 125-241 and 1-124; and f5, 242-342 and 1-124 (Fig. 1). Thus, the main peptides in f1-f5 were considered to be aa 1-241, 125-342, 1-124, 125-241 and $242-342$, respectively, based on the relative amounts of various peptides (as obtained by sequence analysis) in each band. The observed apparent molecular masses of OmpD fragments (see above) were generally comparable to the expected molecular masses of $26 \cdot 7$ (f1), $24 \cdot 2$ (f2), 13.9 (f3), 12.8 (f4) and 11.4 (f5) $\mathrm{kDa}$ as deduced from the NmpC sequence of E. coli (Blasband et al., 1986). The association of a small peptide (307-342) with a much larger peptide (1-241) in fragment $\mathrm{f1}$ was unexpected; however, such anomalous electrophoretic behaviour has been reported for other OM protein fragments (De Mot et al., 1994). The fact that bands $\mathrm{f} 3, \mathrm{f} 4$ and $\mathrm{f} 5$ have fragments in common might be explained by insufficient separation/excision of these bands $(10.5-15.0 \mathrm{kDa})$ prior to sequence analysis. The partial cleavage of proteins by $\mathrm{CNBr}$ resulting in two or more overlapping peptides, as observed in this study, has also been reported by several other investigators
(Garten et al., 1975; Klebba et al., 1990; Mutharia \& Hancock, 1985; Rawling et al., 1995; Singh et al., 1995); it occurs due to the incomplete cleavage of Met-Ser or Met-Thr sequences which can form homoserine and are therefore not cleaved (Garten et al., 1975; Mutharia \& Hancock, 1985).

\section{Similarity of N-terminal sequences with those of other enteric bacterial porins}

Electrophoretically separated peptides of $S$. typhimurium OmpD were transferred onto PVDF membranes and the fragments $\mathrm{f1}-\mathrm{f5}$ were excised and sequenced. The sequences of the first 19-31 aa were identified, aligned and compared with the known sequences of $\mathrm{NmpC}$ from $E$. coli (Blasband et al., 1986) and S. typhimurium (Hongo et al., 1994) (Fig. 1). As mentioned earlier, the deduced sequence of the NmpC-like protein from $S$. typhimurium is partial (Hongo et al., 1994) and lacks the residues corresponding to the first 58 aa in mature $\mathrm{NmpC}$ and Lc from E. coli. Identical and similar residues among these proteins, and aromatic residues which tend to flank the membranespanning $\beta$ strands, were identified. Since the threedimensional structure of $\mathrm{NmpC}$ is unknown at this time, the prediction of its exposed loops (L1-L8), periplasmic turns (T1-T8) and membrane-spanning $\beta$ strands (S1-S16) was made (Fig. 1) by comparing the sequences of $\mathrm{NmpC}$ with E. coli OmpF (Cowan et al., 1992). Three of these sequences (L4, L5 and L6) correspond to the regions with pronounced differences between the $E$. coli $\mathrm{NmpC}$ and the NmpC-like protein from $S$. typhimurium (Fig 1).

The N-terminal sequence of OmpD which begins with AEVYN ... (aa 1-32) aligned better with OmpC (81\% identity) from E. coli and S. typhimurium than NmpC or Lc (74\%) from E. coli (Table 2). Conversely, the C-terminal sequence (STFVD ..., aa 307-326) was 90 to $95 \%$ identical with the $\mathrm{NmpC}$-like protein from $S$. typhimurium and NmpC and Lc from E. coli, but only $80 \%$ identical with $E$. coli and $S$. typhimurium OmpC. The sequence TFGED ... (aa 242-260) showed the lowest identity (37-47\%) with OmpC from E. coli and S. typhimurium, and $\mathrm{NmpC}$ and $\mathrm{Lc}$ from $E$. coli, but $100 \%$ identity with the $S$. typhimurium NmpC-like protein. It is noteworthy that the TFGED ... sequence corresponds to the externally-exposed loop L6. This is one of the three loops mentioned above that show the greatest divergence of sequences between $E$. coli $\mathrm{NmpC}$ and the $S$. typhimurium NmpC-like protein (Fig. 1). It is clear, based on the near identity ( 63 out of 65 residues) observed in the primary amino acid sequences, that $S$. typhimurium OmpD is

\footnotetext{
Fig. 1. Alignment of $\mathrm{OmpD}$ sequences with folding predictions. $\mathrm{N}$-terminal sequences of the $S$. typhimurium OmpD (middle line) were compared with known amino acid sequences of $E$. coli NmpC (upper line) and the S. typhimurium $\mathrm{NmpC}$-like protein (' $\mathrm{NmpC}$ ') (bottom line). The residue numbers assigned to peptides refer to those of $E$. coli $\mathrm{NmpC}$ (Blasband et al., 1986). Boldface dots indicating deletion of amino acid residues and extra sequences are included in the $E$. coli and S. typhimurium proteins to obtain the best-fit alignment (Best Fit algorithm; Genetics Computer Group, Madison, WI, USA). Identical ( $\mid)$ and similar (:) residues among the proteins are shown; aromatic residues are underlined. The externally exposed loops (L1-L8), periplasmic turns (T1-T8) and membrane-spanning $\beta$ strands (S1-S16) were predicted by a comparison of the $\mathrm{NmpC}$ sequence with the three-dimensional structure of $E$. coli OmpF (Cowan \& Rosenbusch, 1994; Jeanteur et al., 1994).
} 
Table 2. Comparison of amino acid sequences of OmpD with those of other bacterial porins

\begin{tabular}{|lccccc|}
\hline OmpD sequence* & \multicolumn{5}{c|}{ Identity (\%) } \\
\cline { 2 - 6 } & $\begin{array}{c}\text { S. typhimurium } \\
\text { 'NmpC' }\end{array}$ & $\begin{array}{c}\text { E. coli } \\
\text { NmpC }\end{array}$ & $\begin{array}{c}\text { E. coli } \\
\text { Lc }\end{array}$ & $\begin{array}{c}\text { E. coli } \\
\text { OmpC }\end{array}$ & $\begin{array}{c}\text { S. typhimurium } \\
\text { OmpC }\end{array}$ \\
\hline AEVYN ... (31) & - & 74 & 74 & 81 & 81 \\
TGRTT ... (26) & 96 & 85 & 88 & 73 & 65 \\
TFGED ... (19) & 100 & 47 & 42 & 37 & 37 \\
STFVD ... (20) & 95 & 90 & 90 & 80 & 80 \\
Overall (96) & $\mathbf{9 7}$ & $\mathbf{7 5}$ & $\mathbf{7 5}$ & $\mathbf{7 0}$ & $\mathbf{6 8}$ \\
\hline
\end{tabular}

* See Fig. 1. The numbers in parentheses indicate the total number of residues identified in the peptide. $\dagger$ The $\mathrm{N}$-terminal sequences of $\mathrm{CNBr}$-generated fragments of $S$. typhimurium $\mathrm{OmpD}$ were aligned with known sequences using the Best Fit program of the University of Wisconsin Genetics Computer Group. The percentage identity was calculated on the basis of the number of residues identified in OmpD. The sequences of other bacterial porins were taken from the following references: $S$. typhimurium NmpC-like protein ('NmpC'), Hongo et al. (1994); E. coli NmpC, Blasband et al. (1986); E. coli Lc, Blasband et al. (1986); E. coli OmpC, Mizuno et al. (1983); S. typhimurium OmpC, Puente et al. (1989), Singh et al. (1995).

identical to the hypothetical translation product of what was named ' $n m p C$ ' of this organism. The two mismatches could be due to errors in either DNA or protein sequence determinations, or, alternatively, the sequence polymorphism due to $S$. typhimurium strain differences.

Overall, and as expected, the OmpD sequence also showed a high degree of identity with $\mathrm{NmpC}(75 \%)$, Lc $(75 \%)$ and OmpC (70\%) from E. coli, and OmpC (68\%) from $S$. typhimurium (Table 2). Similarly, the amino acid compositions of $S$. typhimurium $\mathrm{OmpD}$, despite some differences in the number of Asx, Glx, Gly and Lys residues, showed considerable similarity with $\mathrm{NmpC}$ from E. coli (data not shown). These results are consistent with our earlier report (Singh et al., 1992) that OmpD is immunologically more related to $\mathrm{NmpC}$ and Lc porins of $E$. coli than OmpC from E. coli and S. typhimurium.

We do not know why $S$. typhimurium constitutively expresses OmpD in addition to the general porins OmpC and $\mathrm{OmpF}$, or what role OmpD plays in the physiology or pathogenesis of this organism. The expression of NmpC in $E$. coli $\mathrm{K}-12$ is prevented because of a IS 5 insertion (Blasband et al., 1986); possibly, in S. typhimurium the $o m p D$ gene is expressed because such an insertion sequence is absent in this organism.

\section{mAb reactivity with $\mathrm{CNBr}$-generated fragments}

The OmpD protein from $S$. typhimurium was digested with $\mathrm{CNBr}$, electrophoresed and transferred to nitrocellulose paper. The fragments were analysed for their immunoreactivity with a panel of 16 anti-OmpD mAbs. Each antibody gave a strong positive reaction with the undigested OmpD monomer in Western blots (data not shown), and the panel was classified into three distinct groups on the basis of its immunoreactivity with $\mathrm{CNBr}$ generated peptides in Western blots (Table 3).
Group I contained two mAbs (DM 51.1 and 62.1) that reacted with band $\mathrm{f} 1, \mathrm{f3}, \mathrm{f} 4$ and $\mathrm{f} 5$ (Table 3 ); failure of these antibodies to bind $\mathrm{f} 2$ indicates that the epitope(s) recognized by these mAbs is localized to transmembranous $\beta$ strands S1-S3, between residues 1 and 124 (Fig. 1). Group II mAbs (DM 9.2, 20.2, 22.2, 49.2, 57.2 and 2.1) bound $\mathrm{CNBr}$-generated fragments f1-f5 (Table 3 ), indicating that the epitope recognized by this panel of $\mathrm{mAbs}$ is likely to be localized at or near residue 124 (Fig. 1). This residue is within the eyelet-forming loop, L3 (Cowan et al., 1992; Nikaido, 1992; Struyve et al., 1993) which folds into the barrel leading to the inaccessibility of the epitope on the cell surface. Loop L3 contains one and a half turns of $\alpha$-helix, contributes to the constriction of the pore and is responsible for ion selectivity (Cowan $e t$ al., 1992). The sequence around residue 124 is wellconserved (Fig. 1; Jeanteur et al., 1994; Nikaido, 1992) and, as predicted, all six mAbs in this group cross-react with E. coli NmpC, Lc, OmpC, PhoE, OmpF and Salmonella typhi OmpC (Table 1).

Group III mAbs (DM 12.2, 11.2, 60.3, 26.1, 46.2, 5.1, 19.1 and 24.4) reacted with all $\mathrm{CNBr}$-generated fragments except f5 (Table 3), indicating that the epitope(s) recognized by these $\mathrm{mAbs}$ is likely to be localized on a buried region between residues 125 and 241 (Fig. 1). This region contains membrane-spanning $\beta$ strands S6-S11 (Fig. 1). DM 12.2, 11.2 and 60.3 cross-react with all of the porins tested (Table 1); their epitope is likely to be present on $\mathrm{S} 10$, given the nearly total conservation of amino acids on this strand compared to other $\beta$ strands (Jeanteur $e t a l$., 1994). DM 26.1 and 46.2 also react with all of the porins except E. coli OmpC and OmpF (Table 1); their epitope is possibly localized on $\mathrm{S} 8$ which contains different residues at aa positions 172 and 176 in $O m p C$ and $O m p F$ compared to the rest of the porins tested (Jeanteur et al., 1994). However, DM 5.1, 19.1 and 24.4 bound $\mathrm{NmpC}$ and Lc only (Table 1), their epitope is possibly localized on S9 
Table 3. Reactivity of anti-OmpD mAbs with CNBr-generated peptides of $S$. typhimurium OmpD

Purified porin was digested with $\mathrm{CNBr}$, separated by SDS-PAGE on 10-20\% gradient gels and the peptides transferred to nitrocellulose. The paper was cut into strips which were incubated with individual mAbs, washed and amplified with goat anti-mouse Ig. The strips were then washed and developed with alkaline-phosphatase-labelled rabbit anti-goat $\mathrm{Ig} /$ nitro blue tetrazolium/bromochloroindolyl phosphate (Pai et al., 1992). Reactions were scored as indicated in Table 1, footnote *.

\begin{tabular}{|c|c|c|c|c|c|c|}
\hline \multirow[t]{2}{*}{$\mathbf{m A b}$} & \multicolumn{5}{|c|}{ Peptides } & \multirow[t]{2}{*}{ Probable epitope* } \\
\hline & f1 & $\mathrm{f} 2$ & f3 & f4 & f5 & \\
\hline DM51.1 & ++ & - & + & + & + & \multirow{4}{*}{ TM (S1-S3; aa 1-124) } \\
\hline DM62.1 & ++ & - & ++ & + & + & \\
\hline DM9.2 & ++ & + & ++ & + & ++ & \\
\hline DM20.2 & ++ & + & ++ & + & + & \\
\hline DM22.2 & ++ & ++ & + & + & + & \multirow{2}{*}{ L3 (adjacent to residue 124) } \\
\hline DM49.2 & ++ & + & + & + & + & \\
\hline DM57.2 & + & + & + & + & + & \multirow{10}{*}{$\mathrm{TM}(\mathrm{S} 6-\mathrm{S} 11 ;$ aa $125-241)$} \\
\hline DM2.1 & ++ & ++ & ++ & + & + & \\
\hline DM12.2 & ++ & ++ & + & + & - & \\
\hline DM11.2 & + & + & + & ++ & - & \\
\hline DM60.3 & ++ & + & + & + & - & \\
\hline DM26.1 & ++ & ++ & + & + & - & \\
\hline DM46.2 & ++ & ++ & + & + & - & \\
\hline DM5.1 & + & + & + & + & - & \\
\hline DM19.1 & ++ & + & ++ & ++ & - & \\
\hline DM24.4 & ++ & ++ & + & + & - & \\
\hline
\end{tabular}

* L1-L8, externally exposed loops; TM, transmembrane $\beta$ strands $\mathrm{S} 1-\mathrm{S} 16$, as predicted in the OmpD model (Fig. 1).

since this strand in NmpC and Lc shows significant divergence of sequences (aa 187-191) from other porins.

We have thus identified several buried epitopes on the OmpD porin; these appear to be localized on $\beta$ strands on peptides f3 (DM 51.1 and 62.1; aa 1-124; S1-S3) or f4 (DM 12.2, 11.2, 60.3, 26.1, 46.2, 5.1, 19.1 and 24.4; aa 125-241; S6-S11) or adjacent to residue 124 on loop L3 (DM 9.2, 20.2, 22.2, 49.2, 57.2 and 2.1) (Fig. 1). Although we were unable to identify any surface-exposed epitope, we can, nevertheless, draw significant conclusions from the $\mathrm{mAb}$ reactivity patterns observed in this study. First, $S$. typhimurium OmpD and E. coli $\mathrm{NmpC}$ and Lc are immunologically similar as evidenced by the strong crossreactivity of all $16 \mathrm{mAbs}$ in the panel with these porins (Table 1). This is consistent with our earlier report (Singh et al., 1992) of a close immunological relationship among these proteins. Second, group II mAbs recognize an epitope(s) that is located at or near residue 124 within the eyelet-forming loop, L3 (Cowan et al., 1992; Nikaido, 1992; Struyve et al., 1993). However, this epitope is not accessible on the cell surface (Table 1), indicating that the three-dimensional structure of the porin is essential for an accurate interpretation of $\mathrm{mAb}$ reactivity. The hydropathy analysis can be misleading since we know that the transmembrane strands can be quite hydrophilic due to the alternation of hydrophobic and hydrophilic residues (Cowan \& Rosenbusch, 1994; Cowan et al., 1992; Jeanteur et al., 1994; Nikaido, 1992). Finally, a majority of the mAbs (13 out of 16) showed strong cross-reaction with E. coli $\mathrm{OmpC}, \mathrm{OmpF}$ and $\mathrm{PhoE}$, and $S$. typhi $\mathrm{OmpC}$ (Table 1) and, as stated above, all $16 \mathrm{mAbs}$ reacted strongly with E. coli $\mathrm{NmpC}$ and Lc. These results suggest that the folding model of OmpD, based on the structure of E. coli OmpF (Cowan et al., 1992), is likely to be essentially correct. They further confirm and strengthen the conclusions of several investigators (Cowan \& Rosenbusch, 1994; Cowan et al., 1992; Jeanteur et al., 1994; Nikaido, 1992; Struyve et al., 1993) that the $\beta$ strands in enterobacterial porins are structurally conserved and that the evolutionary divergence of sequences in these proteins is confined to the externally exposed loops. The sequence data presented in this study should be useful in identification of the surface and other buried epitopes which may be important from standpoints of structure-function relationships, diagnostic assays and vaccine developments, including insertion and expression of foreign genes in Salmonella strains (Chatfield et al., 1989; Hackett, 1993; Isibasi et al., 1992; Klebba et al., 1990; Kuusi et al., 1981; Muthukkumar \& Muthukkaruppan, 1993; Puente et al., 1995; Singh et al., 1996; Tommassen et al., 1993). 


\section{Revised map location of ompD DNA sequence}

The ompD locus of $S$. typhimurium was mapped roughly in the 32-33 min region of the chromosome (Sanderson \& Roth, 1988), and more recently at $33.7 \mathrm{~min}$ (now redefined as centisomes, 1 centisome $=1 \%$ ) by physical methods using the ompD159:: Tn10 mutation (Liu et al., 1993; Sanderson et al., 1995). This ompD/nmpC-like locus (see below) of $S$. typhimurium is not equivalent to the $n m p C$ of $E$. coli, which maps in the $12-13 \mathrm{~min}$ region of the chromosome (Pugsley \& Schnaitman, 1978; Lee \& Schnaitman, 1980).

As indicated earlier, OmpD is identical (63 out of 65 residues) to the hypothetical translation product of the $n m p C$-like gene from $S$. typhimurium (Hongo et al., 1994). This sequence identity was further supported when we amplified an internal fragment of the $S$. typhimurium nmpClike gene using PCR primers derived from bp 36-54 and 775-757 (Hongo et al., 1994). We obtained an amplicon of the expected size $(739 \mathrm{bp})$ using the genomic DNA prepared from the OmpD ${ }^{+}$strain $(\mathrm{SH} 7454)$ but not the ompD159:: $\operatorname{Tn} 10$ strains (SH 7455 and SH 7457) (data not shown). This indicates that the mutation caused by the insertion and loss of tetracycline resistance of the ompD159:: $\operatorname{Tn} 10$ strain results in either loss of a primer site or rearrangement that does not allow amplification of the internal fragment specific for the $n m p C$-like gene from SH 7455 and SH 7457. These results further strengthen our view that the $n m p C$-like gene (Hongo et al., 1994) is indeed $o m p D$ that encodes the OmpD protein.

Identification of the $n m p C$-like gene (Hongo et al., 1994) as $o m p D$ now allows us to correct the placement of this DNA sequence (GenBank accession number D26057) on the S. typhimurium genetic map (Sanderson et al., 1995). The previous placement was based solely on the identification of the narK-like gene within D26057 as the narK gene of $S$. typhimurium and an approximation of where the narK gene of $S$. typhimurium would map if it were in the analogous location as in E. coli (K. E. Rudd, unpublished results; Sanderson et al., 1995). However, recently the narK-like gene nar $U$ of $E$. coli has been sequenced (GenBank accession number X94992; V. Bonnefoy, J. Ratouchniak, F. Blasco \& M. Chippaux, unpublished results; Bonnefoy \& DeMoss, 1994) and a comparison of the narK-like gene of $S$. typhimurium with both narU and $n a r K$ of $E$. coli shows that the narK-like gene of $S$. typhimurium is more closely related to nar $U$ than to narK. Protein sequence comparisons indicate that the NarK-like S. typhimurium protein is $78.1 \%$ identical to NarK of $E$. coli (SWISS-PROT accession number P10903) and 85.5\% identical to NarU of $E$. coli (GenBank accession number D26057). In addition, the map location of ompD in $S$. typhimurium is analogous to the map location of nar $U$ of $E$. coli, i.e. between ogt and $d c p$ (Becker \& Plapp, 1992; Berlyn et al., 1996; Sanderson et al., 1995), and is not consistent with the map location of the E. coli narK gene (Berlyn et al., 1996). Therefore, the DNA sequence of the three $S$. typhimurium genes with GenBank accession number D26057 (Hongo et al., 1994) should be placed at the $o m p D$ map location $33.7 \mathrm{Cs}$ and the genes flanking the
S. typhimurium smv $A$ gene in D26057 should be now designated nar $U$ and $o m p D$, not narK and $n m p C$.

\section{ACKNOWLEDGEMENTS}

We thank William Benjamin for advice and assistance with PCR experiments, Shree R. Singh for his help with early phases of this study, Liane Mende-Mueller and Brady Stoner for their assistance with amino acid composition analysis and $\mathrm{N}$-terminal sequencing, Rajeev Misra for helpful comments on the manuscript, Daniel Boyd, Drew Love and Kenya Kearney for their help from time to time during the course of this investigation, P. Helena Mäkelä, John Foulds, Jan Tommassen and Kalle Gehring for the supply of bacterial strains which express specific porins, and Valerie Davis and Brenda Wilson for typing the manuscript.

This work was supported by Public Health Service grant GM 08219 to S.P.S.

\section{REFERENCES}

Becker, S. \& Plapp, R. (1992). Location of the $d c p$ gene on the physical map of Escherichia coli. J Bacteriol 174, 1698-1699.

Bentley, A. T. \& Klebba, P. E. (1988). Effect of lipopolysaccharide structure on reactivity of antiporin monoclonal antibodies with the bacterial cell surface. J Bacteriol 170, 1063-1068.

Berlyn, M. B., Low, K. B. \& Rudd, K. E. (1996). Integrated linkage map of Escherichia coli K-12. In Eschericbia coli and Salmonella typhimurium: Cellular and Molecular Biology, 9th edn, pp. 1715-1902. Edited by F. C. Neidhardt, R. Curtiss, III, J. L. Ingraham, E. C. C. Lin, K. B. Low, B. Magasanik, W. Reznikoff, M. Riley, M. Schaechter \& H. E. Umbarger. Washington, DC: American Society for Microbiology.

Blasband, A. J., Marcotte, W. R., Jr \& Schnaitman, C. A. (1986). Structure of the $l c$ and $n m p C$ outer membrane porin protein genes of lambdoid bacteriophage. J Biol Chem 261, 12723-12732.

Bonnefoy, V. \& DeMoss, J. A. (1994). Nitrate reductases in Escherichia coli. Antonie Leeunenboek 66, 47-56.

Bowden, R. A., Cloeckaert, A., Zygmunt, M. S., Bernard, S. \& Dubray, G. (1995). Surface exposure of outer membrane protein and lipopolysaccharide epitopes in Brucella species studied by enzyme-linked immunosorbent assay and flow cytometry. Infect Immun 63, 3945-3952.

Chatfield, S. N., Strugnell, R. A. \& Dougan, G. (1989). Live Salmonella as vaccines and carriers of foreign antigenic determinants. Vaccine 7, 495-498.

Cowan, S. W. \& Rosenbusch, J. P. (1994). Folding pattern diversity of integral membrane proteins. Science 264, 914916.

Cowan, S. W., Schirmer, T., Rummel, G., Steiert, M., Ghosh, R., Pauptit, R. A., Jansonius, J. N. \& Rosenbusch, J. P. (1992). Crystal structures explain functional properties of two $E$. coli porins. Nature 358, 727-733.

De Mot, R., Schoofs, G., Roelandt, A., Declerck, P., Proost, P., Van Damme, J. \& Vanderleyden, J. (1994). Molecular characterization of the major outer-membrane protein OprF from plant rootcolonizing Pseudomonas fuorescens. Microbiol 140, 1377-1387.

Galanos, C., Luderitz, O. \& Westphal, O. (1969). A new method for the extraction of R lipopolysaccharides. Eur J Biochem 9, 245-249.

Garten, W., Hindennach, I. \& Henning, U. (1975). The major proteins of the Escherichia coli outer cell-envelope membrane: cyanogen bromide fragments of protein I, composition and order. Eur J Biochem 60, 303-307. 
Gehring, K. B. \& Nikaido, H. (1989). Existence and purification of porin heterotrimers of Escherichia coli $\mathrm{K} 12 \mathrm{OmpC}, \mathrm{OmpF}$, and PhoE proteins. J Biol Chem 264, 2810-2815.

Gerbl-Rieger, S., Peters, J., Kellermann, J., Lottspeich, F. \& Baumeister, W. (1991). Nucleotide and derived amino acid sequences of the major porin of Comamonas acidovorans and comparison of porin primary structures. J Bacteriol 173, 2196-2205.

Haase, E. M., Yi, K., Morse, G. D. \& Murphy, T. F. (1994). Mapping of bactericidal epitopes on the P2 porin protein of nontypeable Haemophilus influenzae. Infect Immun 62, 3712-3722.

Hackett, J. (1993). Use of Salmonella for heterologous gene expression and vaccine delivery systems. Curr Opin Biotechnol 4, 611-615.

Highton, P. J., Chang, Y., Marcotte, W. R., Jr \& Schnaitman, C. A. (1985). Evidence that the outer membrane protein gene $n m p C$ of Eschericbia coli $\mathrm{K}-12$ lies within the defective $q s r^{\prime}$ prophage. $J$ Bacteriol 162, 256-262.

Hongo, E., Morimyo, M., Mita, K., Machida, I., Hama-Inaba, H., Tsuji, H., Ichimura, S. \& Noda, Y. (1994). The methyl viologenresistance-encoding gene smvA of Salmonella typhimurium. Gene 148, 173-174.

Isibasi, A., Ortiz-Navarrete, V., Paniagua, J., Pelayo, R., Gonzalez, C. R., Garcia, J. A. \& Kumate, J. (1992). Active protection of mice against Salmonella typhi by immunization with strain-specific porins. Vaccine 10, 811-813.

Jap, B. K., Walian, P. J. \& Gehring, K. (1991). Structural architecture of an outer membrane channel as determined by electron crystallography. Nature 350, 167-170.

Jeanteur, D., Lakey, J. H. \& Pattus, F. (1994). The porin superfamily: diversity and common features. In Bacterial Cell Wall, pp. 363-380. Edited by J.-M. Ghuysen \& R. Hakenbeck. New York: Elsevier.

Kearney, J. F. (1984). Hybridomas and monoclonal antibodies. In Fundamental Immunology, pp. 751-766. Edited by W. E. Paul. New York: Raven Press.

Klebba, P. E., Benson, S. A., Bala, S., Abdullah, T., Reid, J., Singh, S. P. \& Nikaido, H. (1990). Determinants of OmpF porin antigenicity and structure. J Biol Chem 265, 6800-6810.

Kreusch, A. \& Schulz, G. E. (1994). Refined structure of the porin from Rbodopseudomonas blastica. Comparison with the porin from Rbodobacter capsulatus. J Mol Biol 243, 891-905.

Kuusi, N., Nurminen, M., Saxen, H. \& Măkela, P. H. (1981). Immunization with major outer membrane protein (porin) preparations in experimental murine salmonellosis: effect of lipopolysaccharide. Infect Immun 34, 328-332.

Lee, D. R. \& Schnaitman, C. A. (1980). Comparison of outer membrane porin proteins produced by Eschericbia coli and Salmonella typhimurium. J Bacteriol 142, 1019-1022.

van der Ley, P., Kuipers, O., Tommassen, J. \& Lugtenberg, B. (1986a). O-antigenic chains of lipopolysaccharide prevent binding of antibody molecules to an outer membrane pore protein in Enterobacteriaceae. Microb Pathog 1, 43-49.

van der Ley, P., Struyve, M. \& Tommassen, J. (1986b). Topology of outer membrane pore protein PhoE of Eschericbia coli: identification of cell surface-exposed amino acids with the aid of monoclonal antibodies. J Biol Chem 261, 12222-12225.

Liu, S.-L., Hessel, A. \& Sanderson, K. E. (1993). The XbaI-BlnI-CeuI genomic cleavage map of Salmonella typhimurium LT2 determined by double digestion, end labelling, and pulsed-field gel electrophoresis. $J$ Bacteriol 175, 4104-4120.
Lugtenberg, B. \& van Alphen, L. (1983). Molecular architecture and functioning of the outer membrane of Escherichia coli and other gram-negative bacteria. Biochim Biophys Acta 737, 51-115.

Matsudaira, P. (1987). Sequence from picomole quantities of proteins electroblotted onto polyvinylidene difluoride membranes. $J$ Biol Chem 262, 10035-10038.

Mizuno, T., Chou, M.-Y. \& Inouye, M. (1983). A comparative study on the genes for three porins of the Escberichia coli outer membrane: DNA sequence of the osmoregulated ompC gene. $J$ Biol Chem 258, 6932-6940.

Murphy, T. \& Bartos, L. C. (1988). Purification and analysis with monoclonal antibodies of $P_{2}$, the major outer membrane protein of nontypable Haemophilus influenzae. Infect Immun 56, 1084-1089.

Mutharia, L. M. \& Hancock, R. E. W. (1985). Characterization of two surface-localized antigenic sites on porin protein $F$ of Pseudomonas aeruginosa. Can J Microbiol 31, 381-386.

Muthukkumar, S. \& Muthukkaruppan, V. R. (1993). Mechanism of protective immunity induced by porin-lipopolysaccharide against murine salmonellosis. Infect Immun 61, 3017-3025.

Nikaido, H. (1992). Porins and specific channels of bacterial outer membrane. Mol Microbiol 6, 435-442.

Nikaido, H. \& Vaara, M. (1985). Molecular basis of bacterial outer membrane permeability. Microbiol Rev 49, 1-32.

Pai, S. R., Upshaw, Y. \& Singh, S. P. (1992). Characterization of monoclonal antibodies to the outer membrane protein $(\mathrm{OmpD})$ of Salmonella typhimurium. Can J Microbiol 38, 1102-1107.

Puente, J. L., Alvarez-Scherer, V., Gosset, G. \& Calva, E. (1989). Comparative analysis of the Salmonella typhi and Escherichia coli om $p \mathrm{C}$ genes. Gene 83, 197-206.

Puente, J. L., Juarez, D., Bobadilla, M., Arias, C. F. \& Calva, E. (1995). The Salmonella om $p$ C gene: structure and use as a carrier for heterologous sequences. Gene 156, 1-9.

Pugsley, A. P. \& Schnaitman, C. A. (1978). Identification of three genes controlling production of new outer membrane pore proteins in Escherichia coli K-12. J Bacteriol 135, 1118-1129.

Rawling, E. G., Martin, N. L. \& Hancock, R. E. W. (1995). Epitope mapping of the Pseudomonas aeruginosa major outer membrane porin protein OprF. Infect Immun 63, 38-42.

Sanderson, K. E. \& Roth, J. R. (1988). Linkage map of Salmonella typhimurium, 7th edn. Microbiol Rev 52, 485-532.

Sanderson, K. E., Hessel, A. \& Rudd, K. E. (1995). Genetic map of Salmonella typhimurium, 8th edn. Microbiol Rev 59, 241-303.

Singh, S. P., Smith, L. B., Murray, D. M. \& Riley, J. E. (1987). Influence of cultural conditions on the electrophoretic pattern of envelope proteins of Salmonella typhimurium. In Membrane Proteins: Proceedings of Membrane Protein Symposium, pp. 161-178. Edited by S. C. Goheen. Richmond, CA : Bio-Rad Publications.

Singh, S. P., Upshaw, Y., Abdullah, T., Singh, S. R. \& Klebba, P. E. (1992). Structural relatedness of enteric bacterial porins assessed with monoclonal antibodies to Salmonella typhimurium $\mathrm{OmpD}$ and OmpC. J Bacteriol 174, 1965-1973.

Singh, S. P., Singh, S. R., Williams, Y. U., Jones, L. \& Abdullah, T. (1995). Antigenic determinants of the OmpC porin from Salmonella typhimurium. Infect Immun 63, 4600-4605.

Singh, S. P., Williams, Y. U., Benjamin, W. H., Klebba, P. E. \& Boyd, D. (1996). Immunoprotection by monoclonal antibodies to the porins and lipopolysaccharide of Salmonella typhimurium. Microb Pathog 21, 249-263.

Smit, J., Kamio, Y. \& Nikaido, H. (1975). Outer membrane of 
Salmonella typhimurium: chemical analysis and freeze-fracture studies with lipopolysaccharide mutants. J Bacteriol 124, 942-958.

Struyve, M., Visser, J., Adriaanse, H., Benz, R. \& Tommassen, J. (1993). Topology of PhoE porin: the 'Eyelet' region. Mol Microbiol 7, 131-140.

Sukupolvi, S., Vaara, M., Helander, I. M., Viljanen, P. \& Makela, P. H. (1984). New Salmonella typhimurium mutants with altered outer membrane permeability. $J$ Bacteriol 159, 704-712.

Tommassen, J., Agterberg, M., Janssen, R. \& Spierings, G. (1993). Use of the enterobacterial outer membrane protein PhoE in the development of new vaccines and DNA probes. Zentralbl Bakteriol 278, 396-406.

Verhoef, C., Benz, R., Poon, A. P. W. \& Tommassen, J. (1987). New pore protein produced in cells lysogenic for Escherichia coli phage HK253brk. Eur J Biochem 164, 141-145.

Weiss, M. S., Kreusch, A., Schiltz, E., Nestel, U., Welte, W., Weckesser, J. \& Schulz, G. E. (1991). The structure of porin from Rhodobacter capsulatus at $1.8 \AA$ resolution. FEBS Lett 280, 379-382.

Received 26 April 1996; revised 11 July 1996; accepted 16 July 1996. 